\title{
EL CONJUNTO CONVENTUAL DE SAN FRANCISCO DE QUITO: UN CASO PILOTO DE PROGRAMA DE PATRIMONIO MUNDIAL Y TURISMO SOSTENIBLE. LOS RETOS DE LA GESTIÓN TURISSTICA RESPONSABLE Y LA PARTICIPACIÓN COMUNITARIA
}

Jordi Tresserras Juan

Unesco - Ecuador

\section{Resumen}

Este artículo trata de la gestión y uso turístico del Convento Máximo de San Francisco. Pone énfasis en la búsqueda de un equilibrio entre la conservación de este extraordinario patrimonio y su uso cultural, religioso y turístico.

Palabras clave: equilibrio, conservación, patrimonio, cultura, religioso, turístico.

\begin{abstract}
This article addresses the management and use Maximum tourist Convent of Saint Francis. Emphasizes the search of balance between the conservation of this extraordinary heritage and its cultural, religious and touristic use.
\end{abstract}

Keywords: balance, conservation, heritage, culture, religious tourism. 


\section{Introducción}

La cuestión de la gestión y uso turístico del Convento Máximo de San Francisco de Quito (CSFQ) era uno de los tres ejes básicos del Plan de Gestión para el Conjunto Conventual, cuyo objetivo se fundamentaba en garantizar el equilibrio entre la conservación de su rico patrimonio y el uso cultural, religioso y turístico con miras a su sostenibilidad.

Este componente del plan se realizó a lo largo de los años 2013 y 2015 bajo la coordinación de la Organización de las Naciones Unidas para la Educación la Ciencia y la Cultura (UNESCO), desde su Oficina Regional de representación para Bolivia, Colombia, Ecuador y Venezuela con sede en Quito, y mediante un proceso sostenido y concertado de construcción colectiva entre la Comunidad Franciscana, representada por la Guardianía del Convento Máximo de San Francisco y el Vicariato de la Provincia Franciscana del Ecuador, así como las instituciones responsables nacionales y locales que conformaron junto a las citadas el Comité de Gestión: el Ministerio de Cultura y Patrimonio, el Instituto Nacional de Patrimonio Cultural (INPC) y el Municipio del Distrito Metropolitano de Quito (MDMQ) a través del Instituto Metropolitano de Patrimonio (IMPQ) y la Empresa Pública Metropolitana de Gestión de Destino Turístico (EPMGDT) - Quito Turismo. Como todo el proyecto global, fue financiado por la agencia Cooperación Italiana al Desarrollo, supervisada por la Embajada de Italia en Ecuador. Se ha contado también con la colaboración de la Arquidiócesis de Quito y del Ministerio de Turismo (MINTUR), así como de varias congregaciones religiosas quiteñas y organizaciones del sector privado y otras representativas de la comunidad barrial y ciudadana.

\section{Metodología}

La metodología empleada se basó en la realización de un diagnóstico sobre el estado de la cuestión y la identificación de oportunidades que mediante el consenso y la participación permitieron plantear el plan de acciones a corto, medio y largo plazo en el horizonte 2020. Éste se obtuvo tras un proceso de investigación turística cualitativa y cuantitativa del turismo en el Complejo Conventual de San Francisco centrada en fuentes primarias y secundarias de información, considerando conceptos y variables turísticas como los mercados turísticos (análisis de la demanda y la oferta turística); las estadísticas de visitantes disponibles, tanto del Museo Fray Pedro Gocial (MFPG) como en otros museos-conventuales y el propio centro histórico de Quito y su uso, representación gráfica, descripción, análisis y comparación; entrevistas, reuniones y consulta a los agentes involucrados y análisis de webs, blogs y medios sociales (Facebook, Twitter, Flickr, Panoramio, Tripadvisor); así como el análisis general de las potencialidades y las vulnerabilidades. El borrador resultante del primer informe fue compartido entre los diferentes agentes involucrados en el comité gestor y entidades colaboradoras en tres rondas para su verificación y complementación.

Para la realización del plan de acciones se tuvieron en cuenta los objetivos estratégicos de la Convención para la protección del patrimonio mundial cultural y 
natural (1972), las denominadas 5 Cs $^{204}$. En el año 2007 se incorporó la quinta C a las cuatro previas que articuló la Declaración de Budapest (2002). Ésta precisamente propone reforzar el papel de las comunidades en la implementación de la Convención del Patrimonio Mundial. En 2011 el Centro de Patrimonio Mundial empezó a articular el Programa de Patrimonio Mundial y Turismo Sostenible, como respuesta a la decisión 34 COM 5F.2.205 del Comité del Patrimonio Mundial reunido en Brasilia en su 34ª sesión en 2010. Entre las estrategias clave se encuentra el impulso del desarrollo comunitario que incluye medidas y acciones para ayudarles a estimular el turismo, así como el desarrollo económico, social y cultural. El nuevo programa propone como objetivos:

- Promover la participación de todos los agentes implicados en la planificación, desarrollo y gestión del turismo sostenible del destino, impulsando especialmente el empoderamiento de la comunidad local.

- Facilitar a los agentes gestores del patrimonio mundial programas de capacitación e instrumentos necesarios para gestionar el turismo de forma eficiente, responsable y sostenible basada en el contexto local y sus necesidades.

- Impulsar la calidad y la autenticidad de los productos y servicios generando un comportamiento responsable de los agentes y facilitando la comprensión y la apreciación del concepto de valor universal excepcional y la protección del patrimonio mundial.

Una de las iniciativas del programa es la iniciativa "Personas Protegiendo Patrimonio" (People Protecting Places), que pretende involucrar a una generación de viajeros que se interesan por los lugares que visitan y que buscan que esos sitios estén protegidos para la posteridad.

El proyecto de San Francisco de Quito se considera una acción piloto ya que plantea al turismo como una fórmula para obtener recursos para la conservación del conjunto del Convento Máximo de San Francisco mediante el desarrollo de iniciativas y la generación de experiencias que permiten mantener la vida de la comunidad monástica y continuar su función religiosa y espiritual con las actividades culturales y educativas dirigidas al conjunto de la comunidad local, sin que esta se sienta excluida. Se valoró asimismo establecer sinergias con iniciativas de la comunidad organizada como el Buró del Centro Histórico que agrupa al empresariado o Caminos de San Roque ${ }^{206}$, una iniciativa de turismo comunitario barrial. En este sentido Villamil Gualinga (2013) señala que en el Plan Nacional para el Buen Vivir, el turismo comunitario está considerado como eje transversal de la econo-

204 Las 5 Cs corresponden a credibilidad, conservación, capacitación, comunicación y comunidad(es).

205 Decisión 34 COM 5F.2:"the World Heritage Centre to convene a new and inclusive programme on World Heritage and Sustainable Tourism, with a steering group comprising interested States Parties and other relevant stakeholders, and also requests the World Heritage Centre to outline the objectives and approach to the implementation of this programme"

206 Este proyecto de turismo comunitario inició en 2007, impulsado por la Asociación de Guardianes del Patrimonio de San Roque, iniciativa de la comunidad vecinal del barrio de San Roque, con la colaboración de Gescultura en la conceptualización, diseño y gestión y el apoyo del Hotel Casa Gangotena y el museo Casa del Alabado. www.caminosdesanroque.com 
mía popular y solidaria. Del mismo modo se contempla en el Plan Estratgico de Desarrollo del Turismo Sostenible de Ecuador.

Para el desarrollo del proyecto se tuvo en cuenta también el enfoque de realizar una mirada transversal de las convenciones UNESCO (López Morales \& Vidargas 2013; Sandoval 2013) y realizar un enfoque para propiciar el desarrollo comunitario a través del turismo sostenible. Se trata en definitiva de (re)plantear políticas que armonicen sinergias y acciones que satisfagan los objetivos de salvaguardarlo, conservarlo y valorarlo y a la vez construir mancomunadamente productos y servicios que consoliden los destinos patrimoniales como territorios con identidad cultural, polos culturales de calidad, sostenibles y competitivos, inclusivos y generadores de desarrollo cultural, económico y social desde y para la comunidad (Sandoval 2013; UNTWO 2006).

Se trabajó también con el enfoque de la economía naranja propuesto por Buitrago y Duque (2013), incorporando también el concepto de "turismo naranja" que se definió como un turismo sostenible y generador de desarrollo cultural, económico y social a partir de la gestión turística responsable del patrimonio cultural, la producción artística y las industrias culturales y creativas (Tresserras 2013, 2014, 2015). Se tomaron también en cuenta los efectos negativos que puede generar el turismo si no se toman en cuenta medidas de sostenibilidad cultural u complejidad y riqueza y que pueden generar exclusión (Gascón y Cañada 2005; Rosas 2013).

A propuesta de las instituciones religiosas se establecieron sinergias con los principales objetivos de la Pastoral de Turismo propuesta por el Pontificio Consejo para la Pastoral de los Emigrantes e Itinerantes / Pastoral de Turismo en el marco del VII Congreso Mundial de Pastoral de Turismo (Cancún, México - 2327 de abril de 2012):

- Promover una cultura del turismo ético y responsable, de modo que llegue a ser respetuoso con la dignidad de las personas y de los pueblos, accesible a todos, justo, sostenible y ecológico.

- Cuidar la acogida y organizar las visitas turísticas siempre desde el respeto al lugar sagrado y a la función litúrgica para la se crearon muchas de las obras que nacen de la fe y que expresan la fe.

- Acompañar a los cristianos en el disfrute de las vacaciones y tiempo libre, de modo que sean de provecho para su crecimiento humano y espiritual.

El proyecto se complementó con acciones de fortalecimiento de las capacidades de los agentes del sector cultural y turístico de Quito, con programas de formación y asistencia técnica que se realizaron entre 2013 y 2015.

\section{El contexto: el turismo en el Centro Histórico de Quito}

Desde 1967, una ordenanza municipal protege el Centro Histórico de Quito. Quito y Cracovia (Polonia) fueron los primeros centros históricos inscritos en la lista de Patrimonio Mundial de la UNESCO en 1978. La lista, que fue creada ese mismo año, es el principal instrumento de la Convención para la Protección del 
Patrimonio Mundial, Cultural y Natural de la UNESCO, adoptada en 1972, que supervisa y controla el Comité del Patrimonio Mundial instaurado en 1974, con el asesoramiento de instituciones como el Consejo Internacional de Monumentos y Sitios (ICOMOS), el Centro Internacional de Estudios para la Conservación y la Restauración de los Bienes Culturales (ICCROM) y la Unión Internacional para la Conservación de la Naturaleza (IUCN). Quito forma hoy parte activa de la Organización de Ciudades Patrimonio Mundial.

En 1987 fue sacudida por un terremoto que afectó las edificaciones. El congreso creó en diciembre de ese año el Fondo de Salvamento del Patrimonio Cultural (FONSAL), transformado actualmente en el Instituto Metropolitano del Patrimonio (IMPQ). A partir de ese momento se estructura un plan de acción por parte del Municipio de Quito con el diseño de un Plan Maestro inscrito en el Plan del Distrito Metropolitano y que incluye la recuperación del CHQ y entre las acciones señala la promoción del turismo como uno de los componentes del plan vinculado a la generación de oportunidades de empleo y desarrollo para la comunidad. Se buscaron alianzas y mecanismos de financiamiento a través del FONSAL, donde fue básico el crédito del Banco Interamericano de Desarrollo (BID) y el desarrollo de un trabajo en red con varios agentes de la cooperación internacional. El CSFQ fue uno de los conjuntos monumentales beneficiados del programa.

En 1996 empieza a operar la Empresa del Centro Histórico, organismo de economía mixta creado con el proyecto del BID que promovió el plan de seguridad del CHQ e iniciativas culturales desde 2001 como el Festival Internacional de Música Sacra y el programa Quito Eterno.

Cabe considerar en relación con este proyecto instrumentos realizados como el Plan Maestro de las Áreas Históricas de Quito y el Plan Estratégico 1999-2005, que fueron básicos para la activación patrimonial y su inserción como atractivo turístico (MDMQ 1999). Sin duda la reubicación del comercio informal en mayo de 2003 fue el primer logro. El Plan Especial del Centro Histórico (2003), realizado en colaboración con la Junta de Andalucía, definió un programa de ocio, recreación y turismo que promovía la promoción de la oferta turística del CHQ (MDMQ/Junta de Andalucía 2003). En los subsiguientes Plan Equinoccio 21 (2004-25) y Plan Bicentenario (2005-2009) se retoman los lineamientos del Plan Especial tomando como una prioridad la valorización patrimonial y la apropiación del mismo por parte de la comunidad (MDMQ 2004a, 2004b).

Sin duda alguna fue clave la creación en 2002 de la Corporación Metropolitana de Turismo de Quito (CMT), que decidió como primer paso para su organización y gestión la preparación de un Plan Estratégico de Turismo que incluía tanto el desarrollo, como el marketing y la propia organización de la CMT. Chías Marketing Systems junto con Truñó y Asociados participaron en la preparación del plan que se denominó "Plan Q" para el periodo 2003-07. El asesoramiento de Josep Chías continuó en la fase de implantación y progresivo desarrollo hasta la definición y estrategia del "Plan Q 2012” para el periodo 2008-12, cuyos resultados palpables se están cosechando y se está procediendo a su evaluación por parte de Quito Turismo (Chías 2007). 
El Plan Bicentenario, por su carácter operativo, se inscribe dentro de los lineamientos del Plan Equinoccio 21, y promueve la inserción del turismo como una de las líneas estratégicas para dinamizar la economía del CHQ mediante la articulación con el Plan Q. Uno de los objetivos básicos es desarrollar infraestructuras básicas y servicios directamente relacionados con el uso turístico que mejoren la creación de oportunidades de empleo y la oferta de productos turísticos, contribuyan a mejorar la calidad de vida de la comunidad y generen satisfacción a los visitantes (MDMQ 2012b).

El Plan Q 2012 se ajustó a los contenidos y estrategias del Plan estratégico de desarrollo del turismo sostenible en Ecuador hacia el año 2020 - PLANDETUR 2020 del MINTUR, al Plan de Marketing Internacional del Fondo Mixto de Promoción Turística de Ecuador (que luego se adaptó a los Planes Integrales de Marketing Turismo para el turismo interno e internacional, PIMTE 2014) y al Plan Bicentenario del DMQ (Chías 2007; MDMQ 2004b; Mintur 2007, 2009a, 2009b).

En el PLANDETUR 2020 del MINTUR se valoró al CHQ - Patrimonio Mundial como producto A de alto valor potencial vinculado a los segmentos mercado RICE (reuniones, incentivos, conferencias y exposiciones) y turismo cultural, con sus subsegmentos o nichos con potencial para el destino urbano: patrimonio cultural, mercados y artesanías, gastronomía, fiestas populares y turismo religioso, en un escenario de desarrollo turístico sostenible (Mintur 2007).

El 5 de mayo de 2010 se creó la Empresa Pública Metropolitana de Gestión de Destino Turístico (EPMGDT), mediante la ordenanza no 309, denominada Quito Turismo. La creación de sinergias a diferentes escalas de gobierno y público-privadas fue fundamental para el logro de objetivos comunes. Con este plan se fortalece la marca "Quito Patrimonio de la Humanidad" 207 con el eslogan "Toca el cielo". El CHQ se consolida como atractivo turístico por excelencia de Quito. Los operadores lo incorporan a sus ofertas ya sea como visita panorámica o incluyendo la visita de los templos y museos más importantes.

En junio de 2012 se presentó el Plan Estratégico 2012-15 de la EPMGDT - Quito Turismo creado "en función de dos ejes estratégicos esenciales: la implementación de las mejores prácticas de gobierno corporativo y la sostenibilidad fundamentada en una visión estratégica compartida con los grupos de interés primarios" (EPMGDT 2012a).

Dos de los objetivos se centran en incrementar el índice de satisfacción y experiencia del turista en el destino (VP) y el impacto económico del turismo en el $\mathrm{DMQ}$, para ello es fundamental desarrollar una gestión y coordinación adecuadas de facilitación turística, identificar y desarrollar nichos de mercado, desarrollar ofertas turísticas competitivas, implementar productos turísticos innovadores y aumentar la efectividad de los canales de promoción y difusión del destino, incidiendo especialmente en desarrollar la estrategia digital para comercializar el destino y sus productos.

En el espacio monumental de la plaza de San Francisco fue uno de los ejes de actuación, junto con las calles que bordean el conjunto conventual, con la mejo-

207 Para el entorno UNESCO en español la traducción habitual de World Heritage ha sido Patrimonio Mundial. 
ra de la seguridad y la organización de actividades como Quito a pie, la ciclovía patrimonial, noches patrimoniales, rutas teatralizadas o paseos en carruajes de caballos. En este sentido en el marco de las acciones de la Capital Americana de la Cultura Quito 2011 se procedió a la elección de los 7 tesoros del Patrimonio Cultural Material de Quito. Los ciudadanos los eligieron por este orden: la Estación de Ferrocarril Chimbacalle, la Iglesia de la Compañía de Jesús, la Iglesia de San Francisco, la Basílica del Voto Nacional, la Iglesia de la Virgen del Quinche, la Plaza Grande y la Virgen del Panecillo. Los votos procedían de todo Ecuador aunque mayoritariamente correspondieron a la provincia de Pichincha (MDMQ 2012).

La rehabilitación de la calle La Ronda, en el sur del CHQ ha supuesto una clara apuesta por generar un polo de atracción turística que concentre actividades culturales, comercio artesanal, restaurantes de cocina quiteña y vivienda rehabilitada.

Mediante los diferentes planes se articula en el CHQ la creación de una planta hotelera con estándares internacionales dirigida básicamente a captar al turismo extranjero, creando un polo diferencial frente a la zona de la Mariscal que había sido hasta el momento el principal nodo de concentración de alojamiento turístico.. El primero de ellos fue el Hotel Patio Andaluz y le fueron siguiendo otros como el Hotel Plaza Grande, de la cadena Swissôtel, y el Hotel Casa Gangotena ${ }^{208}$ en la misma Plaza San Francisco. Se han mantenido también la red de hoteles económicos ocupados por el turista local y por los agentes de comercio.

Quito se convirtió para los organismos internacionales en un modelo y un ejemplo de cómo las inversiones en centros históricos y equipamientos patrimoniales y las sinergias público-privadas pueden generar un desarrollo sostenible (Arízaga 2002). El Banco Interamericano de Desarrollo (BID) convirtió también el caso quiteño en un laboratorio que sirvió para replicar iniciativas simulares (Rojas 2012; Rojas \& Lanzafanne 2011). Así es que el Banco Mundial lo ejemplifica como una de las experiencias exitosas de lo que se ha denominado como "economía de la singularidad" (economics of uniqueness)(Licciardi \& Amirtahmasebi 2012).

El CHQ está habitado actualmente por unas 40.000 personas, con una la población flotante que circula diariamente en el sector que llega a los 200.000 individuos. En el 2012, la ciudad recibió 533.458 visitantes lo que representa un crecimiento del $9 \%$, respecto al 2011. La tasa de ocupación hotelera subió también al $59 \%$. Progresivamente va subiendo escalas en la captación de eventos ocupando actualmente el puesto 83 en el ranking que establece la Asociación Internacional de Congresos y Convenciones. El turismo estadounidenses es el principal destino emisor (87.074 pax), seguido de los países vecinos y destinos europeos como España o Alemania.

Quito ha dejado de ser una ciudad de paso hacia las Islas Galápagos, con-

208 El Hotel Casa Gangotena ha incluido al CSFQ como uno de los iconos en su estrategia de promoción y comercialización. Desde 2009, junto con el Museo del Alabado, contribuyen a financiar las operaciones de limpieza de la Plaza de San Francisco. En Semana Santa organizan un operativo especial ya que el hotel se convierte en un mirador excepcional. El restaurante ofrece un paquete especial que incluye la tradicional fanesca, vinculado con los potajes de bacalao con legumbres de la Semana Santa hispana pero con productos, saberes y sabores ecuatorianos. 
virtiéndose en el principal destino turístico en el Ecuador con un 66\% del total de visitantes y uno de los 10 destinos más importantes en Latinoamérica. En los últimos años se ha realizado una importante labor de promocionar la ciudad mediante viajes de familiarización con operadores y agentes de viajes (fam-trips), prensa (press trips) y agentes de RICE - Reuniones, Incentivos, Congresos y Eventos (RICE trips), espacialmente del mercado americano y europeo. Como reconocimiento a esta labor obtuvo este año 2013 el Premio Word Travel Awards a Quito, como Destino Turístico Líder de Sudamérica.

\section{La gestión del conjunto conventual de San Francisco de Quito}

El CSFQ es un símbolo de identidad para los quiteños ya que San Francisco es el patrón de la ciudad. Junto a la iglesia de la Compañía de Jesús es uno de los iconos y atractivos turísticos del CHQ. Desde el punto de vista religioso, el Convento es la Casa Madre de los Franciscanos y del franciscanismo del Ecuador. Sede de la Provincia Franciscana de San Francisco de Quito.

La recuperación del CSFQ ha sido posible por el trabajo desplegado a lo largo de dos décadas por el INPC, el FONSAL y la Agencia Española de Cooperación Internacional para el Desarrollo (AECID), fundamentalmente a través del Programa de Escuelas Taller, que hoy día prosigue en la ciudad con la Escuela Taller de San Andrés. Las acciones se centraron en la recuperación del patrimonio cultural inmueble, mueble y las zonas ajardinadas de los claustros, así como el proyecto museológico/museográfico del MFPG (INPC/AECID 2011).

El CSFQ ocupa una extensión aproximada de tres hectáreas y media de terreno, delimitado por una muralla que cierra el monasterio en las calles Simón Bolívar, Imbabura y Mideros. La superficie construida es de unos cuarenta mil metros cuadrados. La fachada y entrada principal se encuentra en la calle Cuenca, abierta a la plaza de San Francisco, configurando un espacio social, cultural, religioso, comercial y turístico de la ciudad. La Plaza de San Francisco había sido el antiguo tianguis o tiánguez de la ciudad cuyo heredero es el actual mercado de San Francisco ${ }^{209}$ y un punto de abastecimiento de agua de la ciudad gracias a la fuente central, construida por las obras realizadas por los franciscanos. Ha sido el espacio de concentraciones militares y políticas, y asimismo lugar de encuentro y recreación sociales.

El CSFQ está ubicado administrativamente en el barrio González Suárez, que ocupa buena parte del CHQ, aunque está relacionado con el vecino barrio de San Roque con el que limita y donde se ubica el convento de Santa Clara. Por la división eclesiástica es dependiente de la parroquia de El Sagrario y a su vez de la Arquidiócesis de Quito, Primada del Ecuador.

El CSFQ cuenta con varios recursos y espacios visitables: la plaza con el atrio, la fuente y la estatua de fray Jodoco Rickie; la basílica menor de San Francisco

209 El mercado de San Francisco es considerado el más antiguo de Quito. Fue fundado hace 150 años y estuvo en la Plaza San Francisco. Posteriormente se lo reubicó en lo que hoy es la Plaza Santa Clara (antes llamado mercado de Santa Clara) hasta su definitiva reubicación en las calles Rocafuerte y Chimborazo, sitio en el cual laboran desde el año 1980. 
(que acoge el Santuario del Jesús del Gran Poder en la capilla de Las Almas), la iglesia y convento de San Carlos ((antes San Buenaventura), la capilla de Cantuña (conocida también por la Capilla de la Cofradía de la Veracruz de Naturales o de los Siete Dolores), el convento de San Pablo, que cuenta con espacios singulares como el coro alto, el museo franciscano Fray Pedro Gocial y la antigua cervecería, la segunda más antigua construida en el continente americano y la más antigua que se conserva. Destacan además tradiciones y leyendas como la de Cantuña ${ }^{210}$. Además de las devociones, calendario litúrgico y celebraciones propias destacan actividades impulsadas por el museo, así como el Festival de Música Sacra y el alquiler de espacios para eventos culturales, sociales y empresariales.

En 1978 la inscripción del CHQ de Quito en la lista de Patrimonio Mundial de la UNESCO permitió reforzar y consolidar el convenio de modus vivendi entre el Estado y la Iglesia. El CSFQ es sede de la Curia o Casa Principal de la Provincia Franciscana del Ecuador, y está dirigido por una Guardianía que gestiona el conjunto monástico. El padre guardián es la responsable de las actividades educativas, culturales y turísticas en paralelo al culto. El Museo está dirigido por un fraile franciscano y la administración está a cargo de un laico. Los guías son estudiantes en prácticas. Los ingresos de la caja conventual provienen desde la fundación de la sacristía (pago de servicios religiosos), las limosnas y las herencias. Se suman los arriendos de las tiendas del atrio y la actividad generada por el MFPG.

En relación al modelo de gestión es clave tener en cuenta los orígenes de los museos de arte en los conventos quiteños que configuran una tipología característica: los conventos-museo. Los mercedarios adecuaron desde 1933 un espacio para acomodar la visita a sus colecciones que generaron la apertura del Museo de Arte Colonial en el Convento Máximo de la Merced (1944) como primer museo de este tipo en Quito. La Asamblea Nacional Constituyente de 1945 promulgó en ese mismo año la Ley del Patrimonio Artístico de 1945 y decretó las devoluciones de los conventos de San Francisco y Santo Domingo, ocupados respectivamente por el cuartel y la escuela de Guardias Civiles, a sus respectivas comunidades. Interpuso que sus colecciones deberían permanecer abiertas al público mediando un horario que se formularía entre las órdenes religiosas y la Casa de la Cultura. Si bien para San Francisco el procedimiento se cumplió en el momento, en el caso de Santo Domingo no se hizo efectivo hasta 1952 (PUCE 1978).

La Ley del Patrimonio Artístico de 1945, modificada en 1979, impulsó la consolidación y la creación de los conventos-museo de arte religioso. Al Museo Mercedario se sumó el Museo Franciscano (hoy Museo Franciscano Fray Pedro Gocial) en el Convento Máximo de San Francisco, impulsado por el padre guardián Fr. Jorge Mosquera y, posteriormente, el Museo del Padre Almeida del Convento de San Diego y el Museo Fray Antonio Rodríguez de Guápulo; así como el Museo Dominicano (hoy Museo Dominicano Fray Pedro Bedón), en el Convento de Santo Domingo. Los agustinos hicieron lo propio en el Museo Miguel de Santiago del Convento de San Agustín. Los mercedarios abrieron asimismo un nuevo espacio, el Museo de Arte de la Recoleta del Tejar (1977). A las iniciativas de las órde-

210 La agrupación cultural Cantuña desde el CSFQ organiza una visita teatralizada donde la leyenda también tiene un gran protagonismo. 
nes masculinas se le sumarían posteriormente las comunidades femeninas tras las reformas del Concilio Vaticano II, con el Museo Monacal del Convento de Santa Catalina, el Museo del Convento del Buen Pastor (antigua recoleta dominica de San Juan de la Peña de Francia) y el futuro proyecto del Museo de Santa Mariana de Jesús ${ }^{211}$ en el Convento del Carmen Alto o de San José. El Museo de la Catedral Metropolitana de Quito correspondería al mismo proceso.

La Comisión Pontificia de Cultura expresa la necesidad de conservar la función litúrgica para la se crearon muchas de las obras que nacen de la fe y que expresan la fe bien sea asociada al culto o en museos y colecciones de arte como parte de la denominada via pulchritudinis, camino de evangelización y de diálogo en la sociedad contemporánea actual. En el caso de Ecuador, la Comisión de Liturgia de la Conferencia Episcopal Ecuatoriana es la responsable de fomentar y apoyar la música sacra, el arte sacro y los santuarios.

En el marco de los acuerdos Ecuador - España se pudo realizar la adecuación de las colecciones del CSFQ en el claustro denominado del museo, así como la restauración y conservación preventiva de una buena parte de las mismas. En mayo de 1993 se entregaron a la comunidad franciscana las salas de la galería norte del claustro principal y en octubre de 1995, dos salas y una galería en la crujía occidental del Claustro del Museo, completándose una superficie de exposición de aproximadamente $500 \mathrm{~m} 2$ (INPC/AECID 2011). En el año 2001, a petición del padre Fr. John Castro, se decidió usar la denominación "Fray Pedro Gocial" para identificar al museo franciscano en homenaje a uno de los fundadores de la escuela de artes e introductor de la pintura como disciplina. Con la tercera fase, realizada en 2002, se duplicó la superficie expositiva a 8 salas de exposición y 3 galerías, con más de 1000 m2. El CSFQ alberga una de las colecciones más importante de arte sacro colonial del Ecuador.

El modelo de gestión es similar a otros museos de arte sacro quiteños. Los jesuitas son los únicos que cuentan con otro modelo de gestión, la Fundación Iglesia de la Compañía de Jesús, que gestiona el complejo jesuítico como centro cultural desde la finalización de las obras en 2005.

La gestión del museo está a cargo de la dirección del museo que recae en un monje a cargo, coordinado con la guardianía, el administrador, un guarda y los guías pasantes. Estos últimos son estudiantes en prácticas de las carreras de turismo de las universidades de la ciudad, que suelen permanecer en el museo de tres a cuatro meses, formándose en interpretación y presentación de las colecciones museo y en el montaje de exposiciones temporales. Cuentan desde 2013 con un uniforme que los identifica. Este tipo de personal temporal es habitual en la mayor parte de los museos del país.

El museo cuenta también con la colaboración del Grupo de Guianza Teatralizada Cantuña que realiza todos los viernes el recorrido por el Convento y el Museo, así como otras actividades especiales.

La guardianía, a través del museo, ejecuta los programas educativos, culturales y turísticos y la comercialización de productos y servicios, como el alquiler de

211 Santa Mariana de Jesús forma junto al Santo Hermano Miguel y a Santa Narcisa de Jesús los tres santos del Ecuador. 
espacios para eventos y la venta de productos, básicamente artesanías, publicaciones y CDs musicales. Impulsa también el grupo de Amigos de los Belenes que impulsan la muestra navideña.

El Coro Franciscano está promovido por los hermanos profesos temporales y con la recuperación del órgano existe un gran potencial para impulsar nuevas iniciativas.

El culto al Jesús del Gran Poder, merece una consideración destacada y cuenta con una dirección del culto y una coordinación para el grupo de voluntarios. Estos se reúnen todos los sábados. A partir del Miércoles de Ceniza empiezan a organizar las comisiones y las tareas antes de la procesión del Viernes Santo. El voluntariado se encarga de montar y decorar las andas de los pasos del Jesús del Gran Poder, la virgen de los Dolores y San Juan. Las estructuras fueron construidas en 1957 sobre el chasís de dos vehículos, son impulsadas a mano y tienen un sistema básico de dirección y frenos.

\section{Grado de estructuración y articulación del CSFQ con el mercado turístico quiteño}

En relación con el destino Quito, según Del Pino (2010, 2013) en el CHQ coexisten dos circuitos:

- Circuito 1 - "City tour" en el CHQ. Iniciado a partir de los años 70 con el inicio del turismo en Quito. Recorrido a pie en el área entre la plaza de la Independencia y la plaza de San Francisco, con acceso a la colina del Panecillo para disponer de una visual panorámica sobre la ciudad. La Iglesia de la Compañía y el conjunto de San Francisco se posicionan como los principales iconos, así como la Iglesia de El Sagrario. Destinado tanto para el turismo nacional como para el internacional. Las visitas son básicamente diurnas, con una duración de 3 horas.

- Circuito 2 - La Ronda. Iniciado 2007. Frecuentado básicamente por el turismo nacional, con potencial internacional con una duración de $2 \mathrm{~h}$ de promedio y hasta $4 \mathrm{~h}$ si realiza alguna actividad. Es un circuito básicamente nocturno.

Estos circuitos se modificaron con la articulación del Quito Tour Bus con un sistema de buses diurnos y nocturnos, estos últimos con parada en La Ronda, que ha aportado el tour panorámico que sirve también para impulsar nuevos recorridos por parte de los participantes.

La consolidación de La Ronda ha generado que desde 2012 el city-tour a Quito haya unificado los dos circuitos mencionados anteriormente para seguir el circuito peatonal por el CHQ desde la Plaza de la Independencia, con la visita a la Catedral, el Palacio de Gobierno y Arzobispal, la Iglesia de la Compañía de Jesús, el Sagrario, el barrio de La Ronda y la Iglesia de San Francisco, continuando hasta el Mirador del Panecillo. Las agencias suelen hacer el traslado en autocar desde el norte de Quito que concentra la mayor parte de hoteles, realizando un punto de parada en la basílica del Voto Nacional, y siguiendo el traslado hasta el CHQ. Tras la visita realizan el ascenso hasta el Panecillo. 
Los turistas ubicados en hoteles del CHQ tienen la opción de realizar el city-tour tradicional, así como visitas para conocer las comunidades donde están ubicados, caso por ejemplo del Hotel Casa Gangotena que promueve los tours de turismo comunitario Caminos de San Roque.

La mayor parte de las agencias de turismo receptivo que organizan city-tours al CHQ e incluyen iglesias y conventos únicamente realizan tours panorámicos, sin ingresos al interior.

La investigación realizada por Del Hierro (2012) sobre la movilidad espacial del turista extranjero en el CHQ muestra que éstos se concentran en los arcos y nodos formados por la calle García Moreno - Plaza de San Francisco, que no superan los 700 metros y los 90 minutos de visita, y que es donde se concentran los principales atractivos: Plaza Grande, Iglesia de la Compañía, CSFQ y Palacio de Gobierno.

Desde el punto de vista de la gestión turística el CSFQ forma parte de varias redes como la Red de Iglesias de Quito, la Red de Museos del Centro Histórico, el Sistema Metropolitano de Museos y Centros Culturales (SIMMYCC), los Santuarios del Ecuador (SANEC), así como de acciones e iniciativas como el Festival Internacional de Música Sacra, las exposiciones navideñas de belenes quiteños, noches patrimoniales o ciclovías patrimoniales. Así mismo se comercializa en circuitos a pie, en bicicleta, carroza o bus turístico.

\section{La demanda turística en el CSFQ}

El público actual del CSFQ es posible agruparlo en cinco grandes grupos:

\section{Religioso}

- Comunidad franciscana residente e invitados.

- Fieles y devotos asistentes regulares al culto en el templo.

- Voluntarios y devotos del Santuario de Jesús del Gran Poder.

- Coro Franciscano.

- Asociación de belenes.

- Comedor y atención social.

\section{Educativo}

- Estudiantes de primaria y secundaria

- Estudiantes de la Facultad de Teología, adscrita a la Universidad Católica de Cuenca.

- Visitantes locales de centros docentes de primaria, secundaria y centros universitarios al MFPG

\section{Cultural}

- Visitantes locales al MFPG 
- Asistentes a eventos culturales y exposiciones temporales del CSFQ y/o MFPG

\section{Turístico}

- Visitantes nacionales y extranjeros al MFPG que compran su entrada en taquilla

- Visitantes nacionales y extranjeros que llegan al MFPG en grupos de turismo receptivo turístico local.

\section{Investigadores y profesionales}

Los estudios de público existentes corresponden al MFPG y recogen datos básicos con un desglose de visitantes por mes y año que separan las ventas en taquillas de las visitas en grupo a cargo de agencias de turismo receptivo. Si bien se desglosan en las ventas en taquilla adultos, estudiantes y niños, únicamente en algunas series se especifica si son nacionales o extranjeros. Por tanto una de las acciones del proyecto debe ser el establecer una ficha base para la toma de datos que permita ser de utilidad en el futuro para mejorar la planificación y la gestión.

No se han realizado hasta el momento estudios de frecuenciación de los espacios de acceso libre de la Basílica de San Francisco y la Capilla de Cantuña.

Tampoco existen en Quito estudios unitarios que permitan conocer la gestión turística del patrimonio religioso de la ciudad. Salvo la Fundación Iglesia de la Compañía, el resto de instituciones suele tener registros aproximados que atribuyen a la insuficiencia de personal y a la falta de capacitación del personal para este tipo de estudios.

La afluencia de visitantes se concentra básicamente en los meses de enero, agosto, noviembre y diciembre. En el caso de los visitantes que lo hacen a través de agencias (mayoritariamente extranjeros) el flujo se concentra en Semana Santa -que recibe unos 40.000 visitantes nacionales y extranjeros-, verano y noviembre. Estos datos son consistentes con las series de Quito Turismo. El incremento de los adultos, estudiantes y nichos en diciembre correspondería también a la exposición navideña del CSFQ. Los usuarios más numerosos son los adultos extranjeros, seguidos de los adultos nacionales, estudiantes nacionales y grupos que contratan agencia receptora (extranjeros). El público infantil es el segmento menos explotado. En el caso de los extranjeros, que son los que contratan agencias, representan entre un 20 y 25\% del total de visitantes. El número total de dichos turistas se mantiene muy estable a lo largo del año aproximadamente 600/700 mensuales, con un ligero incremento en marzo/abril (Semana Santa), agosto y más pronunciado en noviembre, mes en el que superan los 1000 turistas. La tendencia general observada es un incremento del número de visitantes, si bien durante los últimos años se observa un ligero descenso, atribuible básicamente a una reducción del número de adultos y estudiantes, mientras que el público extranjero permanece estable.

Otro de los indicadores empleados para identificar el origen de los visitantes ha sido Tripadvisor. La basílica de San Francisco ocupa la novena posición en el 
ranking de atractivos turísticos de la ciudad ${ }^{212}$ con 189 opiniones de visitantes que nos permiten observar el interés por parte de los quiteños y turistas del complejo. Por las opiniones no todos visitan el museo y algunos participan de las actividades litúrgicas. Los comentarios son por lo general positivos y las críticas son hacia la necesidad de la conservación, la seguridad y una mayor información sobre los horarios y la accesibilidad. En relación con la procedencia de los comentarios analizados de los visitantes no residentes en Quito, entre el 30 de noviembre de 2011 y el 1 de septiembre de 2013 que reflejan las tendencias señaladas en el estudio de Quito Turismo, dominan el mercado estadounidense y el europeo, seguido del latinoamericano y canadiense, aportando incluso datos sobre visitantes del Pacífico, con varias contribuciones de Australia y Nueva Zelanda. La plaza de San Francisco ocupa el $17^{\circ}$ lugar en el ranking de Tripadvisor y el MFPG el $n^{\circ} 41$. Sobre este último únicamente hay cinco comentarios.

\section{Promoción y comercialización}

El elemento clave en la promoción de Quito es que ha empleado como marca "Quito Patrimonio de la Humanidad", posicionando el CHQ como elemento diferencial y articulador de su oferta siguiendo la estrategia del plan Q 2012.

\section{Promoción}

El CSFQ dispone, a través del MFPG, de un programa de actuación en la intermediación turística que consiste en la generación de facilidades a las agencias de turismo receptivo y guías para la realización de visitas. Las reservas se realizan por vía telefónica o correo-e.

Los canales de promoción empleados por el MFPG son los roll-up colocados sobre el museo y la visita guiada teatralizada en la portería de acceso al convento y entrada del museo, así como un folleto promocional. En 2013 presentó la nueva página web www.museopedrogocial.org y la presencia activa en medios sociales como twitter ${ }^{213}$ y facebook ${ }^{214}$, así como un spot promocional ${ }^{215}$ de 2'32', donde se da a conocer el museo y el programa de visitas teatralizadas, para ser distribuido en las mismas por medio del canal Youtube ${ }^{216}$ creado en julio de 2013 . El administrador del museo ejerce a la vez de community manager.

Crearon también a "Panchito", un personaje que se empleaba como la mascota de la radio Francisco Stereo, que representaba a un joven fraile franciscano y que era la atracción para actividades infantiles y familiares. Lamentablemente se quemó durante el incendio de la emisora a finales de febrero de 2012. El MFPG

212 Los primeros puestos corresponden al Museo del Alabado, la Iglesia de la Compañía, la Capilla del Hombre, el Centro Histórico y la Basílica del Voto Nacional, por lo que el sexto lugar le corresponde a la iglesia de San Francisco, ya que los anteriores se refieren en genérico al CHQ.

213 https://twitter.com/MuseoFranciscan https:/

214 https://www.facebook.com/fraypedrogocial

215 http://www.youtube.com/watch?v=d-sLq4w4gJc

216 http://www.youtube.com/channel/UCE4ONPHPdoPu9cpPGFE6DxA 
impulsó la creación de "Jodoquito", la nueva imagen del centro museístico especialmente para el público escolar y familiar.

El MFPG realiza acciones promocionales a través de las redes en las que participa. En el caso de la SIMMYCC y la Red de Museos del CHQ, a modo de ejemplo, ofreció visitas gratuitas para las mujeres el día 8 de marzo Día Internacional de la Mujer, promovió la guía teatralizada de Cantuña como uno de los cinco recorridos especiales de las actividades de verano de 2013 en Quito, así como una oferta de 2x1 en el Día de la Cultura Nacional (9 de agosto).

Por lo general los turistas interesados pueden acudir a las oficinas de información de Quito Turismo y les facilitan información sobre el CSFQ, presente como uno de los iconos de la ciudad en el material promocional (mapa de Quito, folletos, DVDs, sitio web).

El CSFQ y el MFPG colaboran con los viajes de familiarización para los operadores turísticos (fam-trips) como los viajes para la prensa (press-trips) organizados tanto por Quito Turismo como por el Ministerio de Turismo.

\section{El convento de San Francisco 3.0.}

El CSFQ como uno de los principales atractivos de Quito se encuentra incluido entre los recursos a potenciar en la estrategia de turismo 3.0 de Quito Turismo que está impulsando estrategias de marketing online y comunicación directa con el cliente. La nueva app de Quito Turismo es un paso más para llegar al turista 3.0 que visita la ciudad y que por medio de los smartphones accede a los puntos de su interés con la ayuda del GPS, el calculador de distancias y la cámara incorporada que permite consolidar lo que se han denominado posicionamiento emocional: conocer qué siente, qué le gusta y qué transmite en cada momento para mejorar la experiencia de otros usuarios presentes y futuros.

El CSFQ, a través del MFPD, ha entrado este 2013 en la generación 2.0., caracterizado por las redes sociales con su presencia con perfiles en Facebook y Twitter y un canal youtube.

El 3.0 permite aprovechar las oportunidades de aportar contenidos de calidad a la nube, relacionadas en este caso con el CSFQ, adaptándolos al target de las personas interesadas, en nuestro caso peregrinos, visitantes y turistas.

La iglesia de San Francisco y el museo se encuentran en el listado de atractivos en Tripadvisor.com pero aún no se ha generado interactividad, siendo uno de los temas a plantear, especialmente, teniendo en cuenta el acuerdo entre el Programa de Turismo Sostenible de UNESCO y Tripadvisor para promover los sitios en la Lista del Patrimonio Mundial.

La implantación en un futuro de una estrategia 3.0 permitirá consultar información al momento y las reservas de la hospedería o las visitas y actividades al MFPG previo pago anticipado. Además facilita y estandariza procesos, permite la atención personalizada al cliente (p.e. mediante consultas por Skype). 
En turismo el community manager del 2.0 ha dado paso al visitor experience manager. Uno de los retos a salvar es el precio de la conexión de datos en itinerancia (roaming), por eso ha valorado el alquiler de terminales en el MFPG para la propuesta de app para el CSFQ.

\section{Comercialización}

El acceso a la Capilla de Cantuña y a la Basílica de San Francisco es gratuito. El museo es el principal espacio turístico y cuenta con acuerdos con empresas de receptivo turístico local. Cabe considerar que el turismo organizado a través de agencias en destino es únicamente del 16\%, pero muchos turistas adquieren tours a través de las recepciones de los hoteles, agentes de viajes y puntos de información turística. Quito se ha ido posicionando como destino cultural ya que hasta el momento había sido un punto en los circuitos andinos, el tour combinado a Galápagos y las actividades de ecoturismo y deportes de aventura.

El MSFG del CSFQ actualmente cuenta con varios acuerdos receptivos como Abercrombie \& Kent DMC, Ecuadorian Tours, Klein Tours, Mallku Expeditions, Metropolitan Touring, así como con El Quinde donde operan guías turísticos metropolitanos y la Fundación Quito Eterno con sus visitas teatralizadas. Metropolitan Touring es el principal operador a lo largo de este periodo que incorpora al CSFQ en su oferta de city-tours generalistas con visitas de corta duración. Es el mismo caso de Ecuadorian Tours como los tours Quito, Quito Colonial, Joyas Escondidas de Quito, de 3 horas de duración, o combinados con la Mitad del Mundo, de 7 horas. Klein Tours y Mallku Expeditions realizan los tours en las escala a Galápagos. Abercrombie \& Kent DMC es un turoperador especializado en turismo de lujo e incentivos, que tiene su oferta centrada en viajes combinados Quito-Galápagos incorpora también al CSFQ en el city-tour general, pero oferta un paquete de viaje de grupo de incentivo a Quito de 6d/5n que incluye una cena de gala en el convento de San Francisco con acompañamiento del grupo de cuerdas de Luis Rameix. La oficina de El Quinde es donde operan guías turísticos metropolitanos bilingües. Por su parte, la Fundación Quito Eterno está especializada en turismo cultural. Desde 2013 "Cantuña, guianza teatralizada" se comercializa en paquete conjunto con la empresa Quito Tour Bus que oferta paquetes de excursiones como el Quito Bus Tour Noches Patrimoniales que incorpora la visita nocturna por el CHQ y la visita teatralizada al museo, o el Tour de Semana Santa que consiste en un recorrido panorámico por las iglesias de Quito y la visita teatralizada al museo.

Quito Turismo, conjuntamente con la Unidad de Turismo y Protocolo de la Policía Metropolitana, ofrece tours guiados peatonales al centro histórico de Quito, diurnos y nocturnos, en español e inglés que incluyen también el CSFQ. Este grupo de profesionales cuenta con la certificación internacional en seguridad turística "Qualitur" con el auspicio del Ministerio de Turismo. También se organizan rutas específicas, como por ejemplo en el solsticio de verano del 21 de junio con un recorrido por los templos donde se producen varios fenómenos.

Otra iniciativa que merece destacar es el Bike City Tour es un producto que nace del proyecto de los Bicipaseos Patrimoniales que se ofrece para satisfacer 
las necesidades de los turistas extranjeros y nacionales mediante rutas al Centro Histórico de Quito. Las rutas están dirigidas para grupos de mínimo 5 personas y máximo de 25 , y contemplan un guía, bicicleta, casco y chaleco reflectante, servicio de mecánico en ruta, refrigerio y recuerdo de la ruta. Uno de las como uno de los puntos clave.

El museo participa también con un descuento del 50\% en la Tarjeta Quito City Discover, una iniciativa del Club de Producto Turístico del CHQ, con apoyo de la Cámara Provincial de Turismo de Pichincha (CADTUR), el Buró del Centro Histórico y Quito Turismo y la colaboración de la Red Productiva Innovación en el Desarrollo de USAID-Ecuador y Gray-Line Ecuador. Asimismo forma parte del Pase y el Pase y el Pasaporte Museos y Centros Culturales Quito.

\section{Potencialidades para el plan de acciones para la gestión turística del CSFQ}

En el marco del plan de acción se instó al Comité de Gestión del CSFQ, el órgano responsable de su implementación, que impulsará las siguientes líneas de trabajo identificadas a partir de las fortalezas y oportunidades:

El conjunto conventual de San Francisco tiene un gran potencial con espacios sacros singulares que en su horario de apertura al público no cuentan con servicios de vistas coordinadas, como la basílica menor de San Francisco que acoge al santuario del Jesús del Gran Poder en la capilla de las Ánimas y el coro donde se ubica el órgano tubular y actúa el coro franciscano y la capilla de Cantuña. El convento de San Pablo y sus claustros acogen el Museo Fray Pedro Gocial que está renovando su programa de actividades y estrategia de comunicación, y conjuntamente con la Guardianía ha dispuesto de una serie del espacio para la realización de eventos. El CSFQ, como espacio de retiro y santuario de peregrinación plantea crear una hospedería monástica para cubrir estas necesidades. Esta línea es de especial interés para Quito Turismo que plantea desarrollar una iniciativa para el desarrollo del turismo religioso en la ciudad en colaboración con la Arquidiócesis de Quito. Esta iniciativa permitiría generar oportunidades de empleo y/o voluntariado y fondos adicionales para el proyecto. La realización de las audioguías es uno de los primeros resultados.

El CSFQ puede impulsar acciones a corto y medio plazo para presentar propuestas de experiencias para este volumen importante de turistas de ocio y de negocios, mayoritariamente individuales y que organizan el viaje por su cuenta y que valora el CHQ como atractivo y tiene interés por las iglesias y los museos. A medio y largo plazo puede ser el vector para el desarrollo de un programa de turismo religioso para Quito recuperando la denominación que tuvo antaño cuando era considerada el claustro de América. Uno de los retos futuros puede ser armar una propuesta que sea valorada por Opera Romana Pellegrinaggi, el turoperador del Vaticano, y otros agentes que trabajan este segmento. La Ruta Espiritual de las Américas ${ }^{217}$ puede ser perfectamente una iniciativa de interés al respecto.

217 La Ruta Espiritual de las Américas es un proyecto Binacional Ecuador-Colombia que integra la Ruta Espiritual/Religiosa de Ecuador promovida por el Ministerio de Turismo de Ecuador y la Ruta de la Fe en Colombia, impulsada por el Ministerio de Comercio, Consumo y Turismo y Proexport. En Ecuador se han configurado tres clusters. El de Carchi-Cotopaxi incluye Quito y el Convento de San Francisco. 
- Proyecto para la promoción del Santuario del Jesús del Gran Poder en el CSFQ.

- Propuesta para la puesta en marcha de una hospedería monástica centrada especialmente en retiros espirituales y en los eventos vinculados con el calendario litúrgico franciscano.

- CHQ Franciscano. Sería importante la generación de sinergias entre los conventos franciscanos del CHQ: San Diego de Alcalá, que además del Museo del Padre Almeida cuenta con su proyecto de centro de convenciones y hospedería, y Santa Clara con su hospedería y proyecto de un obrador de panadería. En Santa Clara se abrió al público excepcionalmente para la exposición "El esplendor del barroco quiteño" en 2011 en el marco de la conmemoración de los 800 años de la fundación de la Orden.

- El MFPG plantea articular acciones de colaboración con el Museo Fray Pedro Bedón del Convento de Santo Domingo y el Museo del Convento de Santa Catalina de Siena para articular una Ruta de Conventos de Quito.

- Proyecto para impulsar un Bachillerato en Artes en la Unidad Educativa Franciscana "San Andrés", como heredero de la Escuela Quiteña. La comunidad franciscana propone para ello el ex edificio de la Comandancia de la Policía.

- Proyecto de la Cervecería. Existe una propuesta de reactivación de la producción de cerveza artesanal, cuya autorización para su elaboración en el CHQ ha sido aprobada.

- Huertas y jardines conventuales.

- Turismo comunitario urbano en el CHQ. Iniciativas de turismo comunitario vecinal, entorno que involucra de forma externa al CSFQ y Santa Clara e incorpora el de San Diego, sería importante generar sinergias para proponer propuestas conjuntas con entidades como Caminos de San Roque o la Red de Gestores Culturales del Centro Histórico.

\section{Los retos de futuro}

Son muchos los retos de futuro para la gestión turística del CSFQ centrado en la conservación y valorización del patrimonio cultural. La clave está en garantizar la sostenibilidad y la viabilidad del proyecto mediante una empoderamiento de las comunidades locales, la conservación de su identidad y su puesta en valor sin caer en la espectacularización y/o banalización, el fortalecimiento de las capacidades locales, y sobre todo, con una buena estrategia de comercialización, que suele ser el talón de Aquiles. Solo así es posible garantizar la gestión turística sostenible y responsable del CSFQ mediante el desarrollo del turismo naranja, incorporando la economía naranja de forma transversal como elemento de diferenciación del destino y de acorde a una visión conjunta de las convenciones relativas a cultura de UNESCO. El Comité de Gestión es el órgano creado para garantizar el plan de gestión aprobado. 


\section{Bibliografía}

Arízaga, D. (2002).- El centro histórico de Quito: una rápida mirada a los procesos de conservación y rehabilitación y a su financiamiento. Disponible en: http://www.wmf. org/html/PDF/Arizaga_Dora.pdf [último acceso: 6.9.2013]

Buitrago P.F. \& Duque Márquez I. (2013). La economía naranja: una oportunidad infinita. Banco Interamericano de Desarrollo. Washington.

Buró de Convenciones de Quito (2013).- Quito. Destino ideal. Quito. 37 p.

Chías J. (Dir.)(2007).- Plan Q 2012. Plan estratégico de turismo de Quito. Informe fases 0 - I y II. Noviembre 2007. Chías Marketing Systems. Barcelona.

Del Hierro Padilla N.A. (2012).- Estudio del comportamiento espacial del turista extranjero en el centro bistórico de Quito como una herramienta para la mejora de la señalética, movilidad y seguridad turística. Tesis de grado en Ingeniería Administración de Empresas Turísticas de la Facultad de Turismo especialización Hotelería. Universidad del Pacífico. Junio 2012. Quito. http://dspace.upacifico.edu.ec/jspui/bitstream/123456789/142/1/60503.pdf [último acceso: $1 / 11 / 2015]$

Del Pino, I. (2010).- Centro histórico de Quito, una centralidad urbana hacia el turismo. FLASCO - Sede Ecuador / Abya Yala. Quito. 146 p.

Del Pino, I. (2012).- "El Centro Histórico de Quito y el Turismo Cultural”, en Revista América Patrimonio 4 http://www.revistaamericapatrimonio.org/ art_3_4.pdf [último acceso: 1/11/2015]

EPMGDT-Quito Turismo (2012a).- Plan Estratégico. Empresa Pública Metropolitana de Gestión de Destino Turístico. Quito Turismo 2012-2015. Quito.

EPMGDT-Quito Turismo (2012b).- Caracterización del turismo receptor en el DMQ. N². Septiembre 2012. Distrito Metropolitano de Quito. Quito.

EPMGDT-Quito Turismo (2012c).- Perfil del turista de negocios y su gasto promedio. Quito Turismo. Quito. 170 p.

EPMGDT-Quito Turismo (2013).- La experiencia del destino turístico. Quito en cifras. Quito Turismo. Abril 2013. Quito.

Gascón J. \& Cañada E. (2005). Viajar a todo tren: Turismo, desarrollo y sostenibilidad. Icaria. Barcelona. 159 p.

INPC /AECID (2011).- Iglesia y Convento San Francisco, una historia para el futuro. Quito.

Licciardi G. \& Amirtahmasebi R. (Eds.) (2012).- The economy of uniqueness. Investing in historic city cores and cultural heritage assets for sustainable development. Urban Development Series. The World Bank. Washington DC

López Morales F. \& Vidargas F. (2013)(Eds). Convenciones UNESCO. Una visión articulada desde Iberoamérica. Instituto Nacional de Antropología e Historia. México. 300 p.

Ministerio de Turismo (2007). Plan estratégico de desarrollo del turismo sostenible en Ecua- 
dor hacia el año 2020. PLANDETUR 2020. Ministerio de Turismo / Banco Interamericano de Desarrollo. Quito.

Ministerio de Turismo (2009a). Plan Integral de Marketing Turístico de Ecuador (internacional)- PIMTE 2014. Quito

Ministerio de Turismo (2009b). Plan Integral de Marketing Turístico para el Turismo Interno de Ecuador - PIMTE 2014. Quito.

Municipio del Distrito Metropolitano de Quito (1999). Plan Estratégico 1999-2005. Quito.

Municipio del Distrito Metropolitano de Quito / Junta de Andalucía (2003).- Centro bistórico de Quito: plan especial. Quito. 112p.

Municipio del Distrito Metropolitano de Quito (2004a). Plan Bicentenario. Plan de Gobierno 2005-2009. Quito.

Municipio del Distrito Metropolitano de Quito (2004b).- Plan Equinoccio 21 - Quito hacia el 2025. Quito.

Municipio del Distrito Metropolitano de Quito (2008).- Quito, productiva y competitiva. Vol 2. Quito.

Municipio del Distrito Metropolitano de Quito (2008). Quito habitable y armónica. Eje territorial. Vol 3. Quito.

Municipio del Distrito Metropolitano de Quito (2009).- Plan de movilidad sostenible. Centro bistórico de Quito. Quito.

Municipio del Distrito Metropolitano de Quito (2012).- Memoria de actividades. Quito Capital Americana de la Cultura 2011. Quito.

PUCE (1978).- "Museos de Quito”, en Revista de la Universidad Católica 19: 82-97. Pontificia Universidad Católica del Ecuador. Quito.

Rojas E. (2012). "Governance in historic core regeneration projects”, en Licciardi G. \& Amirtahmasebi R. (Eds). The economy of uniqueness. Investing in historic city cores and cultural heritage assets for sustainable development. Urban Development Series. The World Bank. Washington DC. pp. 143-181.

Rojas E. \& Lanzafanne F. (Eds.) (2011).- City development. The experiences of ten World Heritage sites. Inter-American Development Bank. Washington DC.

Rosas Mantecón A. (2013).- "¿Patrimonio para la inclusión? Hacia un nuevo modelo de turismo cultural”, en CONACULTA (Coord.). Políticas públicas y Turismo Cultural en América Latina y el Caribe, Cuadernos de Patrimonio Culturaly Turismo 19: 51-59.

Sandoval Rui z A. (2013). "La diversidad de las expresiones culturales y los desafíos de la Convención de 2005”, en López Morales F. \& Vidargas F. (2013) (Eds). Convenciones UNESCO. Una visión articulada desde Iberoamérica. Instituto Nacional de Antropología e Historia. México. pp. 38-47.

Tresserras Juan J. (2013) - "El turismo naranja”. "Ciudades Patrimonio Mundial y Turismo Sostenible”. Conferencia realizada el 20 de noviembre de 2013 en 
el Teatro Macedonio Alcalá de Oaxaca (México), en el marco del XII Congreso de la Organización de Ciudades Patrimonio Mundial de la UNESCO.

Tresserras Juan J. (2014). - "El turismo naranja, el color del turismo cultural y creativo", en Revista de Economía Creativa. Santiago Creativo no 1: 51-52. Programa CORFO del Ministerio de Economía de Chile. Santiago. http:// issuu.com/santiagocreativo/docs/revista_cscl_ed1

Tresserras Juan J. (2015). - "El turismo naranja: el color del turismo cultural y creativo. Rumbo a una alianza estratégica entre los sectores cultural y turístico". Hosteltur - Agosto 2015. http://www.hosteltur.com/comunidad/004289_el-turismo-naranja-el-color-del-turismo-cultural-y-creativo-rumbo-a-una-alianza-estrategica-entre-los-sectores-cultural-y-turistico. html (última consulta 01/11/2015).

Villamil Gualinga G.H. (2013). "Políticas públicas para el turismo comunitario en el Ecuador: caso de la comunidad Kichwa Añangú”, en CONACULTA (Coord.). Políticas públicas y Turismo Cultural en América Latina y el Caribe, Cuadernos de Patrimonio Cultural y Turismo 19: 93-100.

UNWTO (2006). A Report on the International Conference on "Cultural Tourism and Local Communities” (Yogyakarta, Indonesia, 8-10 February 2006). Madrid. 